\title{
Transamazônica - 200 Milhas - Integração Nacional - Novas Fronteiras
}

PAULUS DA SILVA CASTRO

Chefe do Serviço de Demarcação de Fronteiras do Ministério das Relações Exteriores

Dentro do processo de mutação psicossocial a que o mundo está constantemente sujeito, não è de estranhar-se que o ser humano procure novas perspectivas, tentando lançar-se, nos limites de sua configuração geográfica, a certas aventuras que possam sensibilizar a opinião pública local ou inclusive modificar o seu comportamento, no âmbito político internacional, em relação a países vizinhos ou não, conduzindo-o fatalmente a essa meta tão sonhada de confraternização humana ou união dos povos.

Assim é que se assiste hoje a um movimento universal, motivado por um impulso saudável, e cujas raízes, a bem da verdade, dada a heterogeneidade das causas, constituem ainda um mistério, ocultas que estão sob o manto do tão cobiçado arranque para o desenvolvimento sócio-econômico, cuja definição ninguém ao certo sabe equacionar, e talvez melhor assim o seja, pois é evidente o conflito teórico e pragmático que gera quanto aos seus métodos de execução para assegurar os fins colimados, mas que não tem senão em vista desvencilhar-se de uma situação de inferioridade a que se costuma dar o nome de subdesenvolvimento, também conhecida por "país em procesco de desenvolvimento", expressão essa que dá uma idéia mais exata da conjuntura brasileira.

95. País-Continente, com $8.511 .865 \mathrm{~km}^{2}$, e berço de ...... $(3,1 \% 5.000$ habitantes, cuja taxa de crescimento demográfico, \%), é bastante elevada, vivendo êles, de forma desigual, 
espalhados por êsse imenso espaço terrestre, sob a contingência da mais variada sorte de fatôres ecológicos, é perfeitamente natural que surgisse uma reação decorrente dêsse próprio statu quo, para, em resposta aos anseios legítimos do povo brasileiro, racionalizar o seu modus vivendi e adaptar a moldura interna e externa do País às condições impostas pela revolução tecnológica que avassala o mundo dia a dia.

Envolvido ao Oeste por uma faixa terrestre abrangendo $16.453 .548 \mathrm{~km}$ de extensão, que, de norte a sul, ladeia a linha divisória com 10 países, cujos confins mal são conhecidos e em que talvez o homem nunca tenha chegado a pôr os pés em pleno século $X X$, apesar de ter alcançado a Lua, e a Leste por uma orla marítima que alcança $7.408 \mathrm{~km}$, agora acrescido de 200 milhas de mar territorial, totaliza o País uma área soberana de $11.533 .025 \mathrm{~km}^{2}$, tendo Brasília como órgão propulsor, embora a Região Centro-Oeste seja ainda um vácuo geofísico, que lentamente se vai diluindo pela ocupação efetiva e uma crescente ação produtiva, mormente no campo da lavoura e da pecuária, nada mais louvável, pois, diante dêsse triste panorama de desigualdade regional, que a iniciativa de entrecortar êsse "gigante pela própria natureza" com uma rêde infra-estrutural de transportes e comunicações, no sentido de levar às rarefeitas povoações dêsses longínquos rincões do País, de que o grande público talvez nunca tenha ouvido falar, o confôrto e o bem-estar de que desfrutam em grande parte os centros urbanos.

TRANSAMAZONNICA

Não é de hoje que a Amazônia fascina a imaginação, desperta o interêsse ou a curiosidade, aguça o espírito de aventura, tanto de nacionais como de estrangeiros, haja vista a enorme bibliografia existente a respeito. Há uns 70 anos, Euclides da Cunha, numa visão à la Jules Verne, impressionado pela sua grandeza, conclamava os brasileiros a penetrar por êsse imenso deserto e a ocupá-lo, com o fim de integrar a Região ao resto do Pais e, neste sentido, foi, certamente, o precursor desta marcha para o hinterland brasileiro. Em "Contrastes e Confrontos" e "A Margem da História", expressa êle todo o seu pensamento acêrca da terra e da gente da Amazônia, que êle aprendeu a conhecer em sua viagem ao Alto Purus e que é assim definida: "Terra sem história, que cabe a tantas outras regiões, dominadas por um Rio e de que o homem não se apossou definitivamente ainda".

E parece que prevendo a construção da Transamazônica e imaginou ser uma estrada de ferro), assinala: "AOS 
riscos tortuosos do Purus, Juruá e Javari, há de cortar, transversalmente, com uma linha férrea, de cêrca de 726 km, uma grande estrada internacional de aliança civilizadora e de paz". E finalmente, ao referir-se ao Rio Purus, afirma: "Precisamos incorporá-lo ao nosso progresso, do qual êle será, ao cabo, um dos maiores fatôres, porque é pelo seu leito desmedido em fora que se traça, nestes dias, uma das mais arrojadas linhas da nossa expansão histórica".

Estrangeiros, por sua vez, desde a época colonial, sempre tiveram em mira a Região Norte. É de todos sabido que, valendo-se da façanha de Francisco de Orellana, nos primórdios do século XVI, inglêses (Walter Raleigh e Robert North) e holandeses (Jan de Moor e Peter Andriesen) trataram logo de se mover para o Amazonas. Prepostos de emprêsas comerciais, os inglêses se estabeleceram nas cercanias do Oiapoque e os holandeses no Xingu e Tapajós, à procura de tabaco, cana e algodão, artigos êsses de alta cotação na Europa, mas, na verdade, Com o propósito oculto de conquistar senão o de colonizar a Amazônia, pretensão essa contida a tempo por Felipe II da Espanha, uma vez que pelo Tratado de Tordesilhas, tôda essa Região era domínio espanhol, só cabendo a Portugal uma tênue faixa partindo do Atlântico e que chegava à altura de Belém. A união das duas Coroas, de 1580 a 1640 , se freou a ambição de terceiros países, facilitou, por outro lado, a expansão paulatina dos portuguêses em sua faina de ocupação. É verdade que no século XVII surgiram os franceses, também interessados Pela área, o que levou o Senhor La Ravardière a operar na Guiana, situação essa que só findou com a assinatura do Tratado de Utrecht (11-4-1713). Foi, sem dúvida, essa "manifestação de aprêço" pela Amazônia por parte de inglêses, holandeses, franceses, espanhóis e outros que levou Portugal a manmer um cêrco fechado em tôrno da Região, política eminentegrante prática, que permitiu não perigasse a posse lusitana de de parte da Amazônia, não obstante investidas com a visita outros tistas, como é o caso de La Condamine e Humboldt, entre $\mathrm{C}_{\mathrm{ab}}$, ou a chegada de Missões de Independência do Brasil. mico reconhecer, entretanto, que o interêsse de fundo econôpor pela área continua, embora expresso sob outras formas Periêne de vários países, haja vista a triste lembrança da exda bia que sofreu o País com a queda brusca do cultivo borracha natural por volta de 1930. Passadas essas dezenas de anos, volta à baila o mesmo
Problema, agora abordado de forma diversa, para não dizer Oposta, por brasileiros e estrangeiros. Os nossos, não podendo 
escapar à sua própria índole, movidos por um sentimento de comiseração pela desgraça do seu próximo, pela suspeita de interêsses escusos de forasteiros, e principalmente pelo desejo de pôr um têrmo à imagem distorcida de seu País, o "Brasil país do futuro", se viram na contigência, e essa foi a única alternativa encontrada, de acomodar tôdas as partes componentes do País, com tudo que nelas se tem de conhecido ou desconhecido. Os de fora, seduzidos, e outro não podia ser 0 motivo, por interêsses imediatos ou a longo prazo, não cansaram de propor planos mirabolantes, que vão desde a criação do Instituto Internacional da Hiléia Amazônica até o não menos fantástico Projeto de Inundação da Bacia Amazônica, transformada num lago, proposto pelo Hudson Instituto, e de que 0 conhecido futurólogo Herman Kahn foi o mentor intelectual, homem que, ao fazer cálculos à base de computadores eletrônicos, não leva na devida conta as peculiaridades de cada país ou região em seus prognósticos, transformando os homens em verdadeiros robôs.

Preferiu o brasileiro tomar a si a responsabilidade dessa iniciativa e sua correspondente execução e foi, não há dúvida, um grande passo dado, pois desencadeou um movimento quase revolucionário com vistas à aceleração do crescimento econômico do país.

Para dificultar, logo de início, as coisas, parece que a própria composição geofísica da Amazônia, por não ser uniforme, pois, além da chamada Amazônia Clássica, que consta do Pará, Amazônias, Acre, Amapá, Rondônia e Roraima, há ainda a Grande Amazônia (42,07\% do território nacional) que abrange a Rondônia, Acre, Amazonas, Goiás, Pará e Amapá, acrescido do oeste do Maranhão e parte setentrional de Goiás e Mato Grosso, abrangendo uma população de 7.155.626 habitantes, embora seja baixíssima a densidade demográfica $(0,72$ habitante por $\mathrm{km}^{2}$ ), numa área global de $5.033 .081 \mathrm{~km}^{2}$, espaço que dá para 215 milhões de pessoas viverem.

A sua Bacia Hidrográfica $\left(4.797 .717 \mathrm{~km}^{2}\right)$, composta do Rio Amazonas, cujo caudal médio é de 1.173 metros cúbicos por segundo (ou seja $18 \%$ do caudal de todos os rios do muncompreende quase $20 \mathrm{mil}$ quilômetros de rios navegáveis e constitui ainda, grosso modo, 0 único meio de transporte de carga (a baixo custo) ou de pessoas que na sua maioria vivem às margens dos rios, dedicadas atividades primárias, principalmente do extrativismo (o patrimônio florestal da Amazônia ascende a 70 milhões de mónora
cúbicos), isoladas essas povoações umas das outras. Embor 
a temperatura seja relativamente elevada durante o dia, as noites são bastante frescas durante o ano todo, sendo que a média pluviométrica é alta, dadas as fortes precipitações, e provoca a lixiviação dos solos, eliminando aos poucos o humus, caso não seja submetido a contrôle, o processo de deflorestação, com efeito imediato na conservação das terras cuja variedade chega a impressionar. Ao contrário do que se pensa, longe de constituir a Amazônia uma imensa área alagada (que só representa $3 \%$ da área total), a região é dividida em 3 zonas distintas: a do Norte ou serrana (Maciço Guiano); a do Centro ou depressão amazônica é uma planície por onde passa o próprio Rio AmaZonas; a do Sul ou zona das matas que constitui o chapadão setentrional do Planalto Central brasileiro, sendo que o restante não passa de terras onduladas (exageradamente chamadas serras, como é o caso da Serra dos Parecis), algumas cuja fertilidade só agora ficou comprovada (as tais manchas roxas, numa extensão de $20 \mathrm{mil} \mathrm{km}^{2}$ ), à semelhança das terras de São Paulo, Paraná e Santa Catarina, e outras em que se procede a pesquiSas e prospecção de recursos minerais, como é o caso da Serra dos Carajás, onde ficou patenteada a existência de jazidas de minério de ferro, iguais ou maiores à do quadrilátero mineiro. De sua exploração participam a Companhia Vale do Rio Doce e a "United States Steel Company", num investimento de US\$ 450 milhões de dólares, e cuja produção é estimada em 10 ou 15 milhões de toneladas.

Por sua vez, o Nordeste, que compreende o Maranhão, Piauí, Ceará, Rio Grande do Norte, Paraíba, Pernambuco, Alagoas, Sergipe, Bahia e Território de Fernando de Noronha, é Outra Região que pela sua história e pela sua geografia leva o povo brasileiro, decorridos tantos anos, a clamar por medidas de assistência efetiva ao nordestino, cujas condições de vida já são normalmente precárias em todo o sentido, para não falar nos momentos em que se vê assolado pela sêca ocasional, que o reduz à miséria, e o pior de tudo é que, uma vez o mal superado, êle parece cair de nôvo no esquecimento.

Ao contrário da Região Norte, o Nordeste no seu todo é uma zona de profundos contrastes: região plana e baixa no o Nal se vai elevando para o interior (serras). Por outro lado, nhen é unse e bacia do Paranaíba, formada de aluvião e de cuestas), dito (Nansição entre a Amazônia e o Nordeste pròpriamente do-se (Nordeste oriental) formado de serras e chapadas, seguinAtlânti Zona da Mata (terrenos de aluvião) que se estende do ntico (entre o cabo São Roque e a foz de São Francisco) e, 
finalmente a caatinga ou agreste, terra sêca e ondulada que vai até a chapada de Borborema onde começa a Zona do Sertão. Clima semi-árido, apenas úmido no litoral, densidade populacional elevada, chegando a 200 habitantes por $\mathrm{km}^{2}$, chocante distribuição da riqueza em que o poder aquisitivo varia de 0 a 100 , ou seja do sertanejo ao senhor de terras, proprietário de indústria, ou dono de usinas de cana, como é o caso de Pernambuco. A vista dessa situação, o fluxo migratório é principalmente canalizado para a Região-Leste-Sul, provocando inevitáveis choques sociais, pois o índice de desemprêgo ou subemprêgo que resulta dessa fuga é bastante elevado nos centros urbanos onde se concentra um refugo humano, que fica completamente marginalizado, em virtude de seu baixo grau de alfabetização. Como médio, criou-se, há vários anos, a .... SUDENE, órgão planejador encarregado de examinar e aprovar projetos industriais ou não, do interêsse da economia regínal, e, à base de incentivos fiscais, para lá se deslocou um grande número de filiais de fábricas e indústrias da Região Sul (no momento, há 109 projetos agropecuários, no valor de Cr\$ 431 milhões a serem aplicados no amanho da terra, na base de adubos, fertilizantes, fungicidas e inseticidas). Assim mesmo, êsse processo de contenção que, em muitos casos, não surtiu os efeitos esperados, foi incapaz de absorver boa parte da mão-de-obra excedente. Na lavoura, foi bem maior a absorção, uma vez que a estrutura agrária se manteve igual, não obstante as tentativas localizadas de Reforma Agrária. Assim, o resultado dêsse balanço geral acusou um forte contingente de pessoas desocupadas, tanto no meio rural como nos centros urbanos, pois ambos os setores não estavam em condições de aproveitar, como se pretendia, essa enorme fôrça de trabalho ociosa.

Diante dessa dicotomia Norte - Nordeste, e para não sobrecarregar a Região Centro-Sul, mais do que saturada, procurou-se uma saída racional. Não foi, entretanto, da visita do Presidente da República ao Nordeste, que decorreu o lançamento do PIN (Decreto-lei no 1.116, de 16-6-70) consubstanciado, aparentemente, na construção da Transamazônica e da Cuiabá-Santarém, pois há muito se vinha procedendo a estudos, num verdadeiro trabalho de equipe, para solucionar de forma realista e decisiva êsse impasse, mas certamente foi 0 impacto que sofreu o Chefe do Govêrno, ao presenciar, com seus próprios olhos os efeitos desastrados da sêca de 1970, que assolava tôda a região e minava tôdas as energias de seus habitantes, derrotados pela própria natureza, que constituiu $0^{e^{5}}$ 
topim que levou o Govêrno a acelerar o início da execução de uma obra dessa envergadura. Comovido diante dêste panorama desolador, não conseguiu conter-se o Presidente da República e sua própria reação foi manifestada por palavras que traduzem o verdadeiro sentido do povo brasileiro, qual seja, o de afligir-se com o sofrimento humano, generosidade essa de nossa gente que só a dignifica.

Em linhas gerais, o "Programa de Integração Nacional" não passa de um instrumento cujo objetivo específico é entrosar tôdas as atividades produtivas do País, não se limitando, portanto, a um plano de âmbito regional, embora o seu fim imediato tenha sido o de criar condições para dar vida a uma extensa área que não teve ainda o ensejo de valer-se dos benefícios de que desfruta o resto do País. Há um verdadeiro "processo geral de amarração" no esquema proposto, e já em vias de execução.

Numa cruz perfeita, a Belém-Brasília $(2.161 \mathrm{~km})$, que se prolonga hoje até ao Arroio Chuí, complementada por outras rodovias, e a Transamazônica, numa transversal de leste a oeste (mais de 5 mil km), abrem caminho, criando novas fronteiras para o desenvolvimento do país, vinculando ambas o Brasil a Seus vizinhos limítrofes. Curioso é que, apesar dos qüiproquós que essas estradas de rodagem suscitaram e ainda suscitam, a verdade é que comprovado o seu caráter prioritário no panorama nacional, ambas tocaram fundo no sentimento do povo , caso se fizesse uma consulta à opinião pública, a iniciativa mereceria inteiro apoio da população. E a razão é muito simples, a decisão política tomada, em que foram desprezadas quaisquer outras considerações, significa que venceu a nova mentalidade das gerações de hoje que encara os problemas de maior vulto com um toque imediatista de solução, haja vista 0 entusiasmo com que recebeu a Operação Rondon.

Mal ou bem, ninguém irá contestar agora o acêrto ou não da construção da Belém-Brasília em cujo epicentro está a nova Capital do País (535.206 hab.), instalada em caráter irreversíVel, sendo que o ônus que todos os brasileiros por ela estão Pagando não passa de uma quimera do passado, em têrmos de to política moderna. Essa artéria vertical, a ser completamente pavimentada até 1975 , já é um pólo de atração a seu redor, pois de ponta a ponta vai surgindo um sem número de vilas, núcleos ou povoações (que já chega a 82, com cêrca de 2 mido Departamentos, e que está merecendo a atenção especial 
talação de postos de alfabetização), sendo que a média do tráfego (carga e pessoas), bastante expressiva, é constituída em grande parte de veículos pesados (caminhões e ônibus), e ascende a cêrca de 500 automotores por dia.

Os que, aliás, fazem reparo à Transamazônica, talvez sejam os mesmos críticos da Belém-Brasilia, ressaltam, porém, que essa última vincula centros de desenvolvimento sulinos à grande incógnita do Norte e, neste sentido, à prova do contrário, é uma realização que teria sua razão de ser, uma vez que permite o escoamento da produção para áreas de consumo quantitativamente não avaliadas, e por outro lado, faculta ao parque industrial do país o suprimento de matérias-primas de que carece. Não é difícil perceber o raciocinio a que se prende essa corrente de opinião: produção e consumo, oferta e procura, conjugação dos fatôres de produção, tudo isso agindo simultâneamente, e nada mais. Ocorre que tanto essa estrada, como a outra que se projeta, não é um fim em si, pois transcende de objetivos estritamente econômicos. $\bar{A}$ base dessa premissa, chegar-se-ia à conclusão de que, não existindo, na rota RecifeJoão Pessoa - Cruzeiro do Sul, êsses elementos básicos, deixaria de ter sentido o que se propõe, não havendo motivo, portanto, para a construção da Transamazônica.

No que diz respeito à Transamazônica, pròpriamente dita, que implica em serviços de desmatamento, terraplenagem $e$ revestimento, a partir do Recife ou João Pessoa (BR-230 BR-316), chega a Picos (Piauí), onde começa na verdade, prossegue pela BR-230, passando por Floriano, S. Raimundo das Mangabeiras, Balsas, até chegar a Carolina onde entronca com a Belém-Brasília, na cabeceira da ponte sôbre o Rio Tocantins. Cruza êsse rio na cidade de Estreito, onde se inicia efetivamente a sua construção. Logo a seguir, atravessa o Rio Araguaia em direção à BR-153 por onde chega a Marabá, prosseguindo daí até Tucuruí. Desta cidade, dirige-se para Altamira (Pará) cruzando o Xingu, até Itaituba, no Tapajós, e daí, pela BR-406, atinge Lábrea. Construída a BR-317, Lábrea ficou agora ligada a Bôca do Acre, de onde prossegue até Rio Branco pela mesma BR-317 e entronca com a Brasília-Lima, já aberta ao tráfego até Pôrto Velho. Inaugurado o trecho Pôrto VelhoRio Branco (BR-236 e BR-319), em direção ao Peru, passa a rodovia, de Rio Branco em diante, por Sena Madureira, Feijó, Tarauacá e Cruzeiro do Sul, numa extensão aproximada de $700 \mathrm{~km}$ até chegar a Pucalpa, a $129 \mathrm{~km}$ da fronteira brasileira, entroncando com o sistema rodoviário peruano. A sua pista é de 8,3 metros de largura e tem uma faixa de 70 metros de des- 
matamento lateral. Perto de Pôrto Velho, a Transamazônica cruza com a BR-319, Pôrto Velho-Manaus, também aberta ao tráfego. A Transamazônica, além de conectar os terminais dos afluentes do Amazonas em si, tem a vantagem de possibilitar a conjunção da rêde fluvial e rodoviária, onde será procedida a instalação de núcleos coloniais, pois até hoje não se tem acesso senão às margens do rio, e para até lá chegar, leva-se, às vêzes, dias e mais dias. Assim sendo, os habitantes dessas vilas e povoações passarão a ter maiores contatos entre si, pois vivem, no momento, em profundo e completo isolamento, sem falar nas facilidades para o projetado trânsito da mão-deobra excedente do Nordeste para o Norte, fôrça de trabalho essa que, com seu estabelecimento na área amazônica, poderá dedicar-se a atividades agropecuárias ou não, pois bem melhor para êsse fim são as terras semi-úmidas do Maranhão, Pará e Amazonas, assim como as áreas onde já se tem como certa a existência de recursos minerais, do que as semi-áridas do Nordeste, onde é efetiva a assistência do Ministério do Interior, INCRA, Ministério da Agricultura, Ministério da Saúde (com postos sanitários em Pôrto Franco, Marabá, Altamira, Itaituba, Humaitá e Santarém), Ministério da Educação (onde é notável a atuação do MOBRAL), Ministério de Minas e Energia, e o sempre valioso apoio logístico das Fôrças Armadas, pois não é de hoje que se empenham, dentro de suas possibilidades orçamentárias e humanas, para o progresso regional, haja vista a função dos Destacamentos de Fronteiras ou dos Batalhões de Engenharia de Construção, dos Grupamentos de Fuzileiros Navais (Sul e agora Norte do País) e das Companhias da FAB, através da COMARA ou não (basta dizer que além dos 63 aeroportos para transporte e serviços de salvamento ou busca, há 7 aeroportos na Amazônia, construídos ou em construção, quais sejam, os de Macapá, Belém, Manaus, Tabatinga, Cruzeiro do Sul, Rio Branco e Boa Vista, sob a supervisão da Primeira Zona Aérea, com sede em Belém, de onde partiram e ainda partem os famosos Catalinas da FAB).

Por sua vez, a Cuiabá-Santarém, BR-165 (1.648 km), cuja Construção fica a cargo do DVT do Ministério do Exército (Segundo Grupamento de Engenharia de Construção sob a chefia do General Galileu Machado Gonçalves) e do DNER, ao sair da (Mato paraense, chega a Cachimbo, passando por Pôrto Artur Cionados o 8 ? e 9 ? Batalhões de Engenharia de Construção). Essa rodovia tem características próprias, pois vasculha terras completamente virgens, e pelo fato de ser paralela à Belém- 
Brasília, há de constituir um eixo longitudinal de grande importância na penetração da Amazônia, via Estados do Pará e Mato Grosso.

Confirmando o que foi asseverado acima, a construção das duas estradas obedece a um sistema prèviamente estabelecido cujos pontos principais, entre outros, são: 1972

1) prazo: implantação a ser concluída até fevereiro de

2) construção: dividida em trechos de $300 \mathrm{~km}$ entregues à responsabilidade de 10 firmas ao todo, sendo que só na hiléia amazônica pròpriamente dita, há trabalho para 520 dias, e 0 revestimento é primário, por medida de economia;

3) obra de arte: 2 pontes de madeiras nos Rios Araguaia e Xingu, construidas em pontos em que a largura dêsses afluentes navegáveis do Amazonas não chega acima de 100 metros e emprêgo de balsas para larguras maiores;

4) faixa de $10 \mathrm{~km}$ de cada lado da rodovia, reservada ao estabelecimento de núcleos coloniais para execução de projetos de fomento a atividades agropecuárias;

5) custos: 360 milhões de cruzeiros (estimativa), dentro da dotação geral do PIN: 2 bilhões de cruzeiros;

6) as duas estradas são parte de um todo, pois a elas se juntam outras rodovias, dentro do complexo da rêde amazônica ou quase amazônica. A Cuiabá-Pôrto Velho-Rio Branco, já construída, e que ficou a cargo do $5 \circ$ e 9 ? Batalhões de Engenharia de Construção, permitiu, assim, ligar a capital do Acre a Brasília. Por outro lado, há um plano ora em estudo, de integração rodoviária Bolívia-Brasil-Peru, a ser realizado com financiamentos concedidos pelo BID e pela AID. A Pôrto VelhoManaus (BR-319), que passa pelos rios Purus e Madeira, está aos cuidados do Govêrno do Amazonas, devendo ser financiada em parte pela SUDAM.

Desta forma, Manaus, que era ligada ao resto do País por via fluvial (por onde está chegando todo o material e equipamento de construção da Transamazônica) ou aérea, o será também por via terrestre, sendo que da capital amazonense a rodovia prossegue, via Cararaí, até Boa Vista, por outra estrada (BR-174), cuja construção está a cargo do 6 ? Batalhão de Engenharia de Construção. De Boa Vista, já em Roraima, em outro lance, chegará à Venezuela e à Guiana (BR-401), sendo que essa complementação prevê um prazo de 2 a 3 anos para sua 
construção. Com êsse esquema, tanto no sentido Leste-Oeste como na direção Norte-Sul, fica a Amazônia vinculada ao Plano Geral Rodoviário do País, sem falar nas conexões fluviais, o que foi certamente facilitado pelo levantamento hidrográfico do Amazonas desde a foz até Manaus, numa extensão de 720 milhas.

Atrás dêsse plano há uma filosofia de ação política que visa a interiorização do desenvolvimento, o nivelamento dos grandes desequilibrios regionais que prevalecem no País, de que é sofredor o próprio brasileiro, o fomento à atividade agropecuária, a exploração dos recursos naturais, quaisquer que sejam êles, a conjugação de desenvolvimento agrário e do progresso industrial dissociados por motivos que não se justificam, - livre trânsito entre as várias Regiões do País, acabando com os entraves e obstáculos ao escoamento da produção, o que resulta num consumo mais racional e melhor distribuição da renda nacional, cujo efeito imediato é o aumento do poder aquisitivo do povo em geral, e sobretudo daqueles que vivem nesSas áreas e, em última análise, a afirmação do homem brasileiro que deixará de confiar no acaso, ou então de arraigar-se a certos preconceitos de fundo derrotista.

No que diz respeito particularmente à lavoura, acreditou-se durante muito tempo que irrigação no Nordeste se limitava à construção de açudes e por isso não foi essa medida o instrumento adequado para resolver um problema que, por ser demais complexo, se arrasta há vários anos. A aplicação de novas técnicas agrícolas pressupõe o conhecimento prévio da composição dos solos, sua capacidade de produção e o tratamento que requer mediante fertilizantes, adubos ou outros implementos, para que se torne uma atividade rentável. Por sua vez, torna-se imperativo uma completa transformação da estrutura agrária, primeiro passo para a tão falada Reforma Agrária, cujo esquema e regulamento já foram preparados pelo INCRA. Essas considerações são amplamente confirmadas pelos resultados Parciais obtidos, entre outros pelo DNOCS - SUVALE - pois dos 500 mil hectares do País, só foram irrigados 12 mil (2\% do total). Não obstante a existência de todos êsses órgãos oficiais a que se junta a CEIDA, e naturalmente o próprio INCRA, há pouco criado, foi necessário recorrer à assistência técnica por parte das emprêsas particulares estrangeiras, e por sinal, de um país, israel, que, à semelhança do Japão, revolucionou tudo que existe em matéria de técnica moderna a êsse respeito, contratando-se os serviços da Tahal Consulting Engineering Com- 
pany. Para êsse fim foi aberto um crédito de $\operatorname{cr} \$ \ldots . . .$. . 1.491.640.000,00 para o período de 1971-1974. Para 1971, 17.772 hectares de terras deverão ser irrigados.

Dentro dêsse ambiente, pois, dadas as condições ecológicas adversas, clima, educação, elevada densidade demográfica, transportes, condição financeira, orientação técnico-profissional e acentuada diferenciação de classes, é natural que nêle sejam fortes as tensões sociais. Ademais, por não ter sido totalmente levantado o mapeamento geológico da região, as partes componentes de trinômio lavoura-pecuária-indústria não devem ser consideradas cada uma de per si, pois, além de, econômicamente falando, não ser medida que se justifique, tem por efeito favorecer interêsses ou estimular o egoísmo de poderosos grupos, haja vista a reticência demonstrada pelos industriais, particularmente os donos de usinas de cana, em Pernambuco, e na Zona da Mata, e pelos senhores da terra, o que torna mais aguda a problemática social.

Quem não diz que a Transamazônica chegue a transformar, na base do simples impacto, o modus vivendi do sertanejo, acostumado a não importar-se com o sombrio destino que lhe parece reservado, pois como já foi frisado, essa miséria ou inclemência ambiental não é coisa de hoje, fazendo com que se dilua êsse estado de espírito com que encara o seu futuro e procure interessar-se um pouco mais pela presença e atividade produtiva de seu vizinho, seja êle paranaense ou paulista ou um forasteiro, japonês ou não, que à custa de persistência $e$ reiteradas experiências, tôdas elas merecedoras do apoio de organizações comunitárias nacionais ou do país de origem do estrangeiro que lhe prestam adequada assistência técnica $e$ financeira. Não terá fim essa queimada itinerante da mata, cujo objetivo é o de lavrar-se a terra num sistema de pura economia de subsistência ou de produção a favor do fazendeiro? Em vez de todo êsse processo retrógrado, quando é que se decidirá pelo aproveitamento racional da lavoura, conjugados os interêsses do senhor de terra e do colono, o que há de elevar a produção agrícola, em benefício final do País?

Não é à-toa que no Plano Rodoviário Nacional, a Transamazônica cruza a Belém-Brasilia e a Cuiabá-Santarém (em Itaituba), pois o objetivo principal foi entroncar, por meio de um eixo rodoviário, o Nordeste com o Norte e ambos com o Centro, e êste por sua vez com o Sul, vinculando tôda essa rêde terrestre de comunicação com o sistema de navegação fluvial, e esta, afinal, à navegação marítima. De certo modo, tôda essa arti- 
culação responde à crítica formulada pelos que se opõem à iniciativa, ao compararem a Transamazônica, não à Transiberiana mas à "Transmiseriana" sob o pretexto de que ela irá vincular áreas subdesenvolvidas em vez de proceder-se à ligação da Região Norte à Região Sul, onde estão as fôrças ativas de produção e consumo do País. Por outro lado, vale relembrar, que êsse complexo rodoviário passa do âmbito regional para o nacional e dêste para o internacional, pois a rêde vertical e transversal, a que se entroncam outras rodovias, leva o Brasil às fronteiras do Peru, Venezuela e Guianas, na Região Norte, e também à Bolívia, Paraguai, Argentina e Uruguai na Região Centro-Oeste-Sul. A caminhada é certamente longa, fato êsse que não se discute, mas caberá culpa a alguém por ter o País $4.378 .110 \mathrm{~km}$ de comprimento e 4.326 .729 de largura?

Há quem esteja de acôrdo com tôda essa linha de raciocínio, mas, fundado em critério exclusivamente econômico, torna a levantar a questão do preço final dessa produção agrícola ou industrial sem condições de competir no mercado interno ou externo, em conseqüência da pesada carga de frete rodoviário no cômputo total, situação essa que se agrava com o poder aquisitivo relativamente baixo da média do consumidor nacional. E como alternativa propõe: o aproveitamento da rêde natural de navegação fluvial através da conjugação das Bacias $\mathrm{Hi}-$ drográficas do País, em primeiro lugar, e preferência pelo levantamento de uma vasta rêde ferroviária, em segundo lugar, pois embora a estrada de ferro exija, de início, o empate de grandes investimentos, o retôrno do capital é mais rápido pelo lucro liquido e certo que êle garante a uma emprêsa dêsse tipo, com maior capacidade de transporte (volume de carga e pessoas), o que abaixa o custo de forma sensivel, se comparado ao frete rodoviário.

O reparo, à primeira vista, procede inteiramente, mas cabe não esquecer que, no decorrer da história, vários países se defrontaram com as mesmas dificuldades, entre outros, e num passado não muito remoto, a própria América do Norte (de que, atualmente os movimentados filmes de Far West pelo interior estadunidense são um retrato fiel), a principal nação do século $X X$, com a única diferença de que o seu bem de capital humano em boa parte já passara, então, pelo crivo da escola primária, - que não é nosso caso. Ademais, o problema de desigualdade regional não é privativo de países em processo de desenvolvimento econômico, e a "Tennesses Valley Authority" (TVA), cujas 
atividades prosseguem até hoje, é um exemplo típico de correção geofísica de nivelamento sócio-econômico.

Quanto à prioridade a ser dada à construção de estradas de ferro, o curioso é que essa proposta não leva em conta vários pontos:

1) as peculiaridades do próprio país em que, na sua grande maioria, essas estradas pertenceram tôdas elas a companhias estrangeiras (hoje nacionalizadas), que movidas apenas pelo interêsse, nunca procuraram integrar êsse meio de transporte para transformá-lo numa vasta rêde de âmbito nacional, e o resultado é que o Brasil se vê hoje a braço com estradas de ferro, cada uma de bitola diferente, tôdas elas dispersas pelo território nacional, sem a possibilidade de conexão e mesmo 0 recurso ao terceiro trilho, além de ser uma simples opção técnica, se torna inviável na prática, pelo fato de operarem as estradas de ferro em regiões diferentes e afastadas. A solução mesma está na bitola única, o que permitirá num futuro remoto uma articulação ferroviária geral de tôdas as estradas existentes, com outras a serem construídas. Mas só essa simples consideração já dá uma idéia do custo de uma operação como essa (material rodante, pessoal, sistema de entroncamento);

2) nos Estados Unidos, nos áureos tempos do processo de interiorização do país, o transporte se fazia a cavalo ou em diligências que transitavam por caminhos (que nem estradas eram), pois não passavam de veredas ou mesmo picadas. É $O$ que se dá com o Brasil de hoje em determinados lugares;

3) com um atraso de 150 anos, a situação no Brasil se assemelha um tanto à dos Estados Unidos, e já que não é possivel viajar de trem do Recife a Cruzeiro do Sul, ou de Belém a Pôrto Alegre, como é lícito fazê-lo na América do Norte em trens modernos que saem de Nova lorque e chegam a São Francisco, outra alternativa não há senão abrir caminho com estradas de rodagem. Essa é a conclusão a que se chega, depois de examinar a situação in loco e à vista dos recursos disponíveis. A "Marcha para Oeste", de Cassiano Ricardo, deixou de ser um tema livresco para se tornar uma realidade.

A tecnologia moderna e os novos processos científicos vieram facilitar, e muito, a execução dêsse "Programa de Integração Nacional", em terra e no mar, no que toca à colheita de dados e informações precisas a respeito de tipos e constituição de solos, comprovação ou não da existência de riquezas natude solos, comprovação ou não da existência de riquezas nána
rais de tôda espécie sôbre e sob tão extensa área soberana
como a do Brasil. 
Embora o custo dêsses aparelhos seja elevado, o ônus é de certo modo compensador, primeiro, pela redução da mão-deobra, limitada a pessoal de capacitação profissional altamente especializada, e, segundo, porque se trata da aplicação de técnicas modernas, de amplo raio de ação, que facultam o contrôle e identificação à distância de uma variedade de elementos, de particular interêsse no que diz respeito à oceanografia, como será visto adiante, e que, no âmbito militar, além de beneficiar as Fôrças Armadas, científica e estratègicamente falando, permitirá a elaboração de um Orçamento racional para o Exército, a Marinha e a Fôrça Aérea, desde que essa alternativa, é óbvio, não venha a quebrar a perfeita manutenção da Segurança Nacional.

Com o emprêgo de sensores, aparelhos sensíveis a radiações electromagnéticas na região ótica e na região das microondas às radiações luminosas (emulsão fotográfica) e também a outras faixas de radiação do espectro electromagnético, que abrange tanto as radiações de luz como o infra-vermelho, as caloríficas, etc. Essas radiações estão sujeitas a serem captadas à distância (sensor remoto) através de câmaras aerofotográficas, combinação de emulsão, filtros apropriados, ou sensores de faixa ampliada (espectômetros, radiômetros imageadores ultravioleta, altímetros laser e outros).

Sensor remoto "é um dispositivo capaz de captar, registrar ou coletar informações energéticas de forma direta ou indireta, sôbre fenômenos ou objetos situados a distâncias consideráveis do ponto ou local de observação. Entretanto, o têrmo se aplica, preferivelmente, ao instrumental conseqüente ao advento da moderna tecnologia espacial, cujas aplicações repousam, em larga escala, na física moderna".

Há uma grande variação de sensores, pelo visto:

1) o mais simples de todos, a câmara de fotografia (câmaras métricas e câmaras multiespectrais), que, instalada numa informave ou espaçonave, elevada a grandes alturas, fornece Posicãções precisas da superfície terrestre (forma, dimensão, Posição, natureza e estrutura física);

2) aeromagnetômetro, dispositivo já de maior alcance, Pois permite reconhecer elementos da crosta terrestre, de sua superficie, do subsolo e outras profundidades, por isso mesmo Brasiúnte o seu uso na prospecção de lençóis petrolíferos. No aerolé empregado pela LASA e pela PROSPEC em serviços de Qrolevantamento; 
3) e eletromagnetômetro aéreo, que facilita a localização de corpos na crosta terrestre, mas seu aproveitamento é limitado pela altura que não pode exceder 150 metros a partir do solo;

4) o aerocintilômetro, usado para a determinação de depósitos de minérios radiativos;

5) o espectro electromagnético, além das óticas, que ainda está em fase de teste experimental, o que tornará viável o levantamento ou inventário de recursos naturais ou humanos, na terra ou em outros planêtas;

6) o altímetro laser, para medição da distância e altimetria empregado em tarefas de levantamento topográfico e fotogrametria, e dentro de muito breve, em estudos oceanográficos, propagação de ondas e determinação do fundo do mar;

7) radares:

a) sensor ativo ou radar à base de sensoriamento ativo de energia electromagnética de faixa de comprimento de ondas de $1 \mathrm{~mm}$ até alguns metros (Radio Detection and Ranging); Radar de Visada Lateral (Side Looking Radar) para serviços de topografia e aerofotografia; Radar escaterômetro;

b) sensor passivo, sensor de energia electromagnética na região de microondas de origem natural (radiômetros de microondas de televisão e rádio, usados para contrôle da navegação — imageadores de microondas);

8) sensores de energia electromagnética na região das ondas de televisão e rádio, usados para contrôle da navegação marítima e aérea;

9) sensores remotos como, câmara de televisão, instalados em satélites postos em órbita, chamados por isso sensores orb tais, muito usados pela NASA no levantamento de recursos minerais, estrutura e composição de solos e drenagem. Por estarem em espaçonaves em órbita, são bastante velozes e à prova de perturbações atmosféricas.

Todos êsses aparelhos ou instrumentos têm um campo específico de aplicação, entre os quais:

a) agricultura e florestamento;

b) geografia e cartografia;

c) geologia e hidrologia;

d) oceanografia e tecnologia marítima.

Facilitam enormemente a tarefa de mapeamento, principalmente tratando-se de um país com a extensão territorial do 
Brasil. Basta dizer que foi dado o prazo de 10 anos, como tempo necessário para completar a elaboração da carta terrestre dos Estados Unidos, o que exigiria mais de 1 milhão de aerofotografias, mas no caso de serem tiradas em órbita, êsse número ficaria reduzido a 400 . A mesma observação se aplica às fotografias tomadas de satélites em que é visível a superfície do mar, localizadas as áreas de plancton, determinada a temperatura das águas do oceano, o que é de grande interêsse para a economia de um país, dados os seus efeitos na reprodução da fauna pesqueira.

Neste sentido, foi estabelecido um Plano de Cooperação CNAE - (Comissão Nacional de Atividades Espaciais) - NASA, com vistas ao aperfeiçoamento de pessoal, divulgação de técnicas novas e operação dêsses instrumentos. Assim é que, mediante fotografias tiradas da Gemini IX, foi possivel levantar uma fotocarta de grande parte do Chile, Peru e Equador, com a assistência do "U.S. Geological Survey".

Para dar cobertura técnica ao Programa de Integração Nacional foi criado o Projeto RADAM (da importância de $27 \mathrm{mi}-$ thões de cruzeiros), sob a orientação do Ministério das Minas e Energia, através do acôrdo CNAE-NASA, em que será feito o levantamento da topografia, cobertura florestal, geomorfologia, pesquisas de minerais e energéticos, natureza do solo, drenagem e umidade, numa área de quase $1.350 \mathrm{~km}^{2}$, o que cobre parte dos Territórios e Estados do Amazonas, Maranhão, Goiás, Piaui e Mato Grosso, usando-se nesta tarefa o processo de Radar de Visada Lateral (SALR), posto em prática na Transamazônica, no trecho de Pôrto Franco a Humaitá. O emprêgo dessa técnica apresenta as seguintes vantagens:

1) menor prazo de execução;

2) possibilidade da tomada de fotografia ou imagem, via radar, a qualquer hora do dia e noite, sem interferência de perturbação atmosférica, à vista dos resultados obtidos em outros paises com áreas semelhantes à Região Norte;

de técn aquisição de maior experiência nesse campo por parte écnicos brasileiros;

4) custo operacional mais econômico.

O Projeto RADAM compreende 3 frases:

Tôdas reconhecimento da área através de imagens via satélite. obtidas informações captadas são interpretadas pela NASA e obtidas via Gemini; 
2) exploração e cobertura da área num prazo de dois anos, com a obtenção de orto-mosaicos, semicontrolados, cartas e overlays com interpretação relativa à vegetação, drenagem, geologia, solos e geografia;

3) determinação de áreas para sensoriamento detalhado. As áreas selecionadas nas imagens do radar serão sobrevoadas com sensores de detalhamento, com vistas à obtenção de mapeamento multidisciplinar minucioso, terminando com a elaboração de cartas em escalas que permitem o levantamento cadastral dos recursos naturais da região.

O Projeto RADAM deverá ser executado por uma equipe brasileira, com a assessoria da "Earth Satellite Corporation". Antes da tarefa, os técnicos brasileiros submeter-se-ão a um teste prévio na sede da firma acima referida, em Berkeley, Estados Unidos, onde serão treinados para a execução de tôdas as fases do Projeto RADAM.

RECURSOS NATURAIS

Uma simples relação dos recursos naturais, de ordem vegetal, animal e mineral das Regiões Norte e Nordeste, à base de últimos dados e informações colhidas em documentos e publicações do IBGE, Ministério do Interior, Ministério da Agricultura e Ministério das Minas e Energia, dá uma idéia precisa do que essas 2 regiões produzem e do que existe em seus respectivos limites geográficos, em potencial ou não.

\section{REGIÃO NORTE}

\section{Produtos vegetais:}

Juta - 43.256 t $(99,1 \%$ do total) - Pará-Amazonas;

Borrachas - (caucho, hévea, látex, mangabeira, maniçoba) 29.787 t $96,1 \%$ do total) - Roraima, Amazonas, Pará,
Acre;

Pimenta-do-reino - 1.040 t $(94,7 \%$ do total) - Pará (Tomé-Açu);

Castanha - 39.252 t $(77 \%$ do total) - Pará-Amazonas; Malva-Guaxima - 15.249 t - Pará-Amazonas;

Castanha-de-caju - 23.683 t - Pará-Amazonas; Guaraná - 180 t - Pará-Amazonas; Guaraná - $180 \mathrm{t}$ - Pará-Amazonas;
Madeiras - (aguano, cedro, freijó, sucupira, louro e castanhei-
ra) - Pará-Amazonas;

Árvores - (castanheira, seringueira e sumaúma, com 60 metros de altura) - Pará-Amazonas; 
Frutas - (laranjas, tangerinas, limas, abacate, côcos, abacaxis, goiabas, jacas, sapotis, melancias, melões, bananas e açaí) - Amazônia em geral;

mandioca - (farinha d'água);

milho;

feijão;

batata-doce;

cana-de-açúcar;

arroz;

fumo;

cacau.

Produtos animais - (por mil cabeças)

peixes;

suinos - 14.153 (ou seja, $21,8 \%$ do total);

bovinos - 18.786 (ou seja, $20,3 \%$ do total) - principalmente nos Municípios de Santana do Araguaia e Conceição do Araguaia;

asininos - 468.000 (ou seja, $15,6 \%$ do total) - Pará;

aves - Amazônia em geral:

Produtos minerais:

estanho - (cassiterita) (87,3\% do total) - Rondônia;

manganês - 1.623.516 t (ou seja, 77,4\% do total) - Amapá; Ouro - Amapá, Roraima;

diamantes - Amapá, Roraima;

bauxita - Trombetas;

Petróleo - Poços de Nova Olinda, Amazonas;

cobre;

niquel;

chumbo;

mármores;

ferro - (Serra dos Carajás);

aluminio;

Zinco;

cobalto.

REGIÃO NORDESTE

Produtos vegetais:

Sisal - 316.293 t $(95,2 \%$ do total) - Paraíba, Bahia, Rio

Grande do Norte, Pernambuco;
cacau - 163.569 t $(95,1 \%$ do total) - Bahia;

citicica - 36.664 t $(86,9 \%$ do total) - Ceará, Paraíba, Pernambuco; 
babaçu - 59:641 t (90,3\% do total) - Maranhão, Plaú; côcos - 442.494 t $(67,7 \%$ do total) - Bahia, Alagoas, Sergipe, Pernambuco; algodão - 600.154 t (ou seja, $27,9 \%$ do total) - Ceará,

Rio Grande do Norte, Paraíba; mandioca - 9.602.891 t (32\% do total) - Bahia, Maranhão,

Ceará, Pernambuco; bananas - 119.816 t (ou seja, 25,9\% do total) - Bahia,

Pernambuco; cana-de-açúcar - 21.398.364 t (ou seja, 27,4\% do total) -

Bahia, Pernambuco, Alagoas, Paraíba; carnaúba - $17.658 \mathrm{t}$ - Piauí, Ceará, Rio Grande do Norte; piaçava - 22.528 t Bahia; feijão - 543.145 t (ou seja, $22,9 \%$ do total) - Bahia, Ceafumo;

rá, Pernambuco;

arroz.

\section{Produtos animais:}

peixes; peixes; - (por mil cabeças) - 8.336 (ou seja $9,0 \%$ do total)
- Bahia;

caprinos - 11.161 (ou seja, $75,3 \%$ do total) - Bahia, Maranhão, Piauí, Pernambuco, Ceará, Paraíba, Rio Grande do

Norte;

suínos - 9.069 (ou seja, $14,0 \%$ do total) - Bahia, Maranhão; equinos - 971 (ou seja, $10,6 \%$ do total) - Bahia;

ovinos - 6.810 (ou seja, $27,6 \%$ do total) - Bahia, Ceará,
Piauí, Paraíba;

Piauí, Paraíba;
asininos - 1.825 (ou seja, $60,9 \%$ do total) - Bahia, Piaú,
Pernambuco;

Pernambuco;
muares - 1.393 (ou seja, $28,8 \%$ do total) - Bahia, Ceará,
Pernambuco.

\section{Produtos minerais:}

magnesita - 137.820 t (ou seja, 100\%) - Bahia, Ceará; sal -1.114 .913 t (ou seja, $77 \%$ do total) - Rio Grande do Norte, Ceará;

amianto - $273.300 \mathrm{t}$ (ou seja, $80 \%$ do total) - Alagoas; chumbo -230.000 t (ou seja, $71,8 \%$ do total) - Bahia; mármore -5.782 t (ou seja, $14,1 \%$ do total) - Bahia; petróleo - 10.169.964 t (ou seja, $98,9 \%$ do total) - Bahia,

Sergipe, Alagoas; 
Cobre - Na região de Caraíba, Baraúna e Iguruna (Bahia);

ferro;

areias;

antimônio;

mercúrio;

fosfato;

micas;

Cristais.

De acôrdo com o levantamento realizado ou em processo de realização pela Superintendência para o Desenvolvimento da Amazônia (SUDAM), do Ministério do Interior, e pelo Departamento Nacional de Produção Mineral, do Ministério das Minas e Energia, a situação, no momento, na Região Norte, no que diz respeito a pesquisas e investigações, assim como à exploração de produtos minerais é a seguinte:

\section{Zona do Tocantins:}

minério de ferro - Serra dos Carajás (Marabá) cujas reservas ascendem a quase 400 milhões de toneladas.

diamantes - Apesar das técnicas ainda primitivas em uso, eleva-se a produção anual de 10 a 20 mil quilates, numa área aproximada de $100 \mathrm{~km}^{2}$.

manganês - Depósitos localizados nos rios Parauabebas e Itacaiunas.

Carvão de pedras - Em Marabá, ao norte de Goiás e no sul do Maranhão, foram encontradas extensas jazidas dêsse minério.

Pedras semipreciosas - (Marabá e Itupiranga).

Cristal de rocha - (na Bacia dos rios Araguaia, Tocantins (municípios de Barão e Tucuruí) e no rio Itacaiunas (Municípios de Marabá e São João do Araguaia).

rutilo - No Igarapé Grotão da Onça.

berilo - perto do Município de Conceição de Araguaia (ora mica; estudo pelo DNPM).

tantalita:

Zona do Xingu:

ferro - No alto do Rio Fresco, na foz do Rio Naja, e na região de Gorotire.

manganês - Na região de Gorotire, perto do Rio Fresco.

Ouro - De Marabá a São Felix, região aurífera, nos aluviões do Rio Tocantins e afluentes, e no Igarapé Trairão. 
pegmatitas - No Rio Fresco e no Rio da Paz.

asfaltitas - No Rio Fresco. Há um elemento carbonífero que contém níquel e vanádio.

cobre e chumbo - Na Foz do Rio Fresco, há uma associação de calcopirita (sulfato de ferro e cobre) e galena (sulfato de chumbo) argentifera, numa área de $50 \mathrm{mil} \mathrm{km}^{2}$.

\section{Zona do Tapajós:}

ouro - Em aluviões auríferos existentes no Município de Itaituba, na Bacia do Tapajós, Jamanxim, Rios das Tropas, Grepori e cercanias, é intensa a atividade de garimpagem. cassiterita - Na bacia do médio Tapajós até o Rio Madeira, tendo Itaituba como centro.

manganês - Em Itaituba, na região de Munducurânia. gás natural - Em Itaituba foi localizado um campo de gás parafínico por ocasião de pesquisas à procura de petróleo. calcários - Em Itaituba no vale do Igarapé Bom Jardim, em Monte Cristo, e em Aveiro (Santana), assim como em Jacareacanga (na Serra do Cachimbo).

sal-gema - No Rio Tapajós, a serem explorados pela CAITÁ (produção de soda cáustica, cloro e pasta de celulose), foram localizados leitos de sal-gema.

gipsita - No Tapajós e no Rio Cupari, em Pedra Branca, encontra-se gipsita cristalina.

\section{Zona da Madeira:}

manganês - Depósitos localizados entre os rios Aripuană $e$ Sucunduri (reservas talvez maiores que as da Serra do Sucunduri (reservas talvez maiores que as da Serração
Navio) - exploração no Médio Aripuanã pela Minerantim.

estanho - Tapajós até a Bacia do Madeira foi verificada a existência de cassiterita.

Elaborados pela SUDAM e pelo DNPM, cabe fazer referência aos seguintes projetos:

a) Projeto Marabá, que cobre uma área de $75 \mathrm{mil} \mathrm{km}$, e cujo fim é cadastrar os garimpos e acompanhar os trabalhos de prospecção de minério de ferro e de manganês;

b) Projeto Tapajós, realizado pelo Departamento $\mathrm{NaCiO}^{-}$ nal de Produção Mineral, numa área de $40 \mathrm{mil} \mathrm{km}^{2}$, no Médio Tapajós, na pesquisa de cassiterita e no inventário de garim- 
pos de ouro. Na área de Jamanxim, a SUDAM está procedendo a estudos sôbre minérios de cobre, chumbo e zinco.

c) Projeto Aripuanã, Sucunduri, a cargo do DNPM, que orienta as pesquisas em jazidas de manganês e cassiterita.

Para todo êsse Programa foi fixada uma dotação de dois bilhões de cruzeiros, lançando mão o Govêrno, de preferência, de recursos não inflacionários, $30 \%$ oriundos de incentivos fiscais de várias fontes de arrecadação (turismo, pesca, reflorestamento), não procedendo, assim, tal importância de órgãos regionais como a SUDENE e a SUDAM, ainda que fôsse essa a primeira impressão, mesmo porque o empenho de verbas destinadas à SUDENE é duas vêzes maior que o atribuído à construção das duas estradas, sem contar com os financiamentos outorgados por organismos internacionais de crédito. O certo é que, de forma geral, o PIN proverá o País, nas áreas mais neessitadas da infra-estrutura sócio-econômica, que, há muito, faltava e por isso mesmo sua transcendental importância política não se discute. Basta dizer que dêsse plano faz parte também a construção da Hidrelétrica de Curuá-Una, na Cachoeira do Palhão, com 7 milhões, 408 mil cavalos-vapor e cujo custo é orçado em 75 milhões de cruzeiros, sendo que a potência inicial instalada será de ordem de $20.000 \mathrm{kw}$, podendo ser ampliada para $40.000 \mathrm{kw}$.

Dois Programas, um de Integração Nacional e outro de Integração Social, que ambos entrosam e se completam, não mais sujeitos a infalíveis reformulações por parte de cada administração que se sucede, foram lançados, cabendo agora, como já ocorre, dar sentido de continuidade a sua execução, iniciada em boa hora. Esta fase de afirmação é, sem dúvida, de suma importância, e por isso mesmo tôda discussão teórica, que já se arrasta pelos anos adentro, deve ser evitada.

Tudo leva crer que, com o endôsso oficial, se enveredará pelo caminho certo. Montada a infra-estrutura de transportes, educacional, médico-sanitária, financeira, técnica e de capacitação profissional, não há motivo para acreditar que a máquina deixará de movimentar-se a contento, cercada que está das garantias básicas e seus reflexos no meio social de serem promissores.

Este artigo terá prosseguimento no próximo número da REVISTA DO añViço PúBLICO, em seqüência na qual o Ministro Paulus da Silva Castro analisa a fundamentação $e$ as decorrências da extensão do mar territorial r lasileiro para 200 milhas, bem como cita a bibliografia utilizada para a elaboração de todo o texto. 
